\title{
Cytogenetic changes in primary, immortalized and malignant mammalian cells
}

\author{
Stephan Kirchner ${ }^{a}$, Helga Stopper ${ }^{a}$, Thilo Papp ${ }^{a}$, Inge Eckert ${ }^{a}$, \\ Hee J. Yoo ${ }^{b}$, Baldev K. Vig ${ }^{b}$ and Dietmar Schiffmann ${ }^{a}$ \\ ${ }^{a}$ Institut für Toxikologie, Universität Würzburg, Würzburg (Germany) and ${ }^{b}$ Department of Biology, \\ University of Nevada, Reno, NV (USA)
}

Key words: Micronuclei; Kinetochore; Chromosome distribution

\section{SUMMARY}

Some chromosomes in transformed rat cells and somatic cell hybrids fail to display the presence of kinetochore proteins as detected by antikinetochore antibodies. Such chromosomes ( $\mathrm{K}^{-}$chromosomes) may constitute a novel mechanism for the genesis of aneuploidy. We have analyzed primary, immortalized and malignant mammalian cells for the presence of kinetochore proteins and micronuclei. Our results suggest a correlation of the $\mathrm{K}^{-}$chromosome and micronucleus frequency with the variability in chromosome number. Upon in situ hybridization with the minor satellite and alpha satellite sequences some $\mathbf{K}^{-}$ chromosomes showed a signal. This indicates that the observed lack of kinetochores is not necessarily due to a lack of centromeric DNA. We conclude that dislocated $\mathrm{K}^{-}$chromosomes may become incorporated into micronuclei which are prone to loss. Such events would be associated with the generation of aneuploidy.

\section{INTRODUCTION}

The centromeric regions of mammalian chromosomes contain several proteins which constitute the kinetochores [1]. However, recently the existence of chromosomes without such proteins was reported [2]. These akinetochoric chromosomes have been observed in transformed cell lines of rat endothelial origin as well as in somatic cell hybrids of human $\times$ mouse origin [3]. It was suggested that a lack of kinetochore proteins at the site of the centromere may render these chromosomes ineffective during anaphase migration. It is conceivable that some such chromosomes would become incorporated into one of the daughter cells resulting in two cells with

Correspondence to: Dr. D. Schiffmann, Institut für Toxikologie, Universităt Würzburg, Versbacher Str. 9, D-8700 Würzburg, Germany 
unequal chromosome numbers. Some of these chromosomes may become incorporated into micronuclei.

Cells in long-term cultures generally exhibit variability in chromosome number (hypodiploidy/hypertetraploidy), yet the underlying mechanisms are still unknown. Our previous results [4] already showed that the variability in chromosome number correlated with the frequency of $\mathrm{K}^{-}$chromosomes in three mouse cell lines. We now analyzed the arrangement of chromosomes at the spindle periphery in the meta/ anaphase stage of several other mammalian cell lines. Dislocated chromosomes were further analyzed for the presence of centromeric DNA by in situ hybridization. In addition, we investigated the occurrence of micronuclei in six mouse cell lines with different distributions of chromosome number. Our results further confirm the hypothesis that the lack of kinetochores contributes to micronucleus formation and the generation of variability in chromosome number.

\section{MATERIALS AND METHODS}

\section{Chemicals and biochemicals}

Bisbenzimid 33258 and FITC-conjugated goat anti-human antibody were purchased from Sigma Chemical Co., St. Louis, USA. Dimethylsulfoxide (DMSO) was acquired from Aldrich Company Europe, Nettetal, Germany. CREST-Serum (antikinetochore antiserum) was obtained from Antibodies Incorporated, Davis, CA, USA. Anti-digoxigenin detection kit was acquired from Boehringer Mannheim, Germany, and the signal amplification reagent set for biotin detection was purchased from Oncor/Dianova, Hamburg, Germany.

\section{Cell lines and culture conditions}

SHE (Syrian hamster embryo) cells were established as described previously [5]. All experiments were performed with tertiary or quaternary cultures derived from 13day-old Syrian hamster embryos. Cell cultures were grown in humidified atmosphere with $12 \% \mathrm{CO}_{2}$ in air at $37^{\circ} \mathrm{C}$. The culture medium used was IBR-modified Dulbecco's reinforced medium (Gibco-BRL, Eggenstein, Germany) supplemented with $100 \mathrm{U} / \mathrm{ml}$ penicillin and $100 \mu \mathrm{g} / \mathrm{ml}$ streptomycin, $3.7 \mathrm{~g} / 1 \mathrm{NaHCO}_{3}$ and $15 \%$ fetal calf serum (Gibco, Karlsruhe, Germany). Neoplastically transformed SHE B(a)P/TPA were obtained after initial treatment with benzo(a)pyrene and subsequent administration of tetradecanoyl phorbol acetate, as described by Potenberg et al. [6]. All other cell cultures were grown in humidified atmosphere with $5 \% \mathrm{CO}_{2}$ in air at $37^{\circ} \mathrm{C}$. Mouse A9, LA9 (immortalized mouse fibroblasts) and MBT (mouse brain tumor cells) were cultured as described previously [4]. HeLa cells (tumor, human) were cultured in MEM medium containing 10\% fetal calf serum. 3T3, L 929 (immortalized mouse fibroblasts) and N18 (mouse glioma tumor) cells were grown in IBR medium supplemented as described above for SHE cells. L5178Y (mouse lymphoma) cells were obtained from Dr. W. Caspary (NIEHS, Research Triangle Park, USA) and cultured in RPMI, supplemented with $10 \%$ horse serum, $0.25 \mathrm{mg} / \mathrm{ml}$ glutamine, $107 \mu \mathrm{g} / \mathrm{ml}$ 
sodium pyruvate, $95 \mathrm{U} / \mathrm{ml}$ penicillin and $95 \mu \mathrm{g} / \mathrm{ml}$ streptomycin (Gibco-BRL, Eggenstein, Germany).

\section{Metaphase chromosome analysis}

Cells were washed in PBS (phosphate-buffered saline), centrifuged onto glass slides (Cytospin II, $5 \mathrm{~min}$ ), fixed in cold methanol $\left(-20^{\circ} \mathrm{C}, 30 \mathrm{~min}\right)$ and treated with antikinetochore (CREST) serum. FITC-conjugated anti-human IgG (1:100 in PBS) was administered for $45 \mathrm{~min}$. After washing with PBS, ethidium bromide was applied for staining $(1 \mu \mathrm{g} / \mathrm{ml})$ and the slides were mounted for fluorescence microscopy. Meta/ anaphase chromosome ring arrangements and dislocated chromosomes were counted; the presence of kinetochores on these chromosomes was determined.

\section{In situ hybridization}

Cells were centrifuged onto glass slides (Cytospin II) and dehydrated in an ethanol series $(70,80,95,100 \%, 2$ min each) after fixation in cold methanol/acetic acid (3:1, $-20^{\circ} \mathrm{C}, 30 \mathrm{~min}$ ). Prior to hybridization slides were kept for $1 \mathrm{~h}$ at $60^{\circ} \mathrm{C}$ and immersed in $70 \%$ formamide $/ 2 \times \mathrm{SSC}\left(\mathrm{pH} 7.0,2 \mathrm{~min}, 70^{\circ} \mathrm{C}\right.$ ) to denature the DNA. Subsequently, they were again dehydrated as described above. For hybridization, cells were incubated in $50 \%$ formamide $/ 2 \times \mathrm{SSC} / 10 \%$ dextrane sulphate, containing $20 \mathrm{ng}$ of centromeric DNA probe (biotinylated or digoxigenated). Hybridization was performed overnight in a humidified chamber $(2 \times \mathrm{SSC})$ at $37^{\circ} \mathrm{C}$. Immunochemical detection was carried out using an anti-digoxigenin conjugate (Boehringer Kit) or avidin-FITC conjugate, respectively. In the latter case, signals were further amplified with a FITC-labeled anti-avidin antibody (Oncor/Dianova Kit). Chromosomes were counterstained with propidium iodide (Oncor/Dianova Kit) and the slides were mounted for fluorescence microscopy.

\section{Distribution of chromosome numbers}

After hypotonic treatment (10 to $20 \mathrm{~min}$ ) cells were fixed in cold methanol/acetic acid $\left(3: 1,-20^{\circ} \mathrm{C}, 30 \mathrm{~min}\right)$, dropped onto ice-cold glass slides, air-dried and stained with bisbenzimid $33258(5 \mu \mathrm{g} / \mathrm{ml}, 5 \mathrm{~min})$. The slides were mounted for fluorescence microscopy and chromosome numbers were scored.

\section{Micronucleus analysis}

All cells (except L5178Y, which were brought onto glass slides by cytospin centrifugation and thereafter treated accordingly) were grown to medium density on glass coverslips, fixed in cold methanol $\left(-20^{\circ} \mathrm{C}, 30 \mathrm{~min}\right)$ and, after washing with PBS, stained with bisbenzimid $33258(5 \mu \mathrm{g} / \mathrm{ml}, 5 \mathrm{~min})$. Kinetochore staining was achieved by incubating the methanol-fixed cell preparations (after rinsing with PBS) with CREST serum (60 min) in a humidified chamber at $37^{\circ} \mathrm{C}$. After rinsing with PBS again, the cells were incubated as before with FITC-conjugated goat anti-human antibody (diluted 1:100 in PBS), rinsed again and counterstained with bisbenzimid 33258 as described. The slides were mounted for fluorescence microscopy. Micronu- 


\section{TABLE I}

FREQUENCY OF $\mathrm{K}^{-}$CHROMOSOMES DISPLACED FROM METAPHASE RING ARRANGE$\operatorname{MENTS}(n=$ number $)$

\begin{tabular}{|c|c|c|c|}
\hline Cell line & No. metaphase rings & $\begin{array}{l}\text { No. } \mathrm{K}^{-} \text {Chromosomes } \\
\text { off the ring }\end{array}$ & $\begin{array}{l}\text { Rings with } \mathrm{K}^{-} \text {off } \\
\text { (\%) }\end{array}$ \\
\hline SHE & 482 & 2 & 0.4 \\
\hline SHE B(a)P/TPA & 502 & 12 & 2.4 \\
\hline 3T3 A & 1000 & 45 & 4.5 \\
\hline LA9" & 169 & 9 & 5 \\
\hline A9a & 197 & 11 & 6 \\
\hline HeLa & 429 & 21 & 5 \\
\hline $\mathrm{MBT}^{\mathrm{a}}$ & 196 & 20 & 10 \\
\hline
\end{tabular}

Data from Vig et al. [4].

clei were scored as such when up to three per cell were present. Cells with higher numbers of micronuclei were not registered.

\section{RESULTS}

\section{Analysis of dislocated metaphase chromosomes}

We have investigated the metaphase ring arrangements in primary Syrian hamster embryo (SHE) cells, neoplastically transformed SHE cells (SHE B(a)P/TPA), the mouse cell line 3T3 A and the human tumor cell line HeLa S3. We have analyzed the metaphase ring arrangements for dislocated chromosomes and for the presence of kinetochore proteins, detected by anti-kinetochore antiserum. We compared the results with our previous data [4] obtained with the mouse cell lines LA9, A9 and MBT (Table I). In primary SHE cells we observed displaced $\mathrm{K}^{-}$chromosomes in only $0.4 \%$ of the rings, whereas neoplastically transformed SHE cells (SHE B(a)P/TPA) exhibited a 6-fold increase in the frequency of such structures. In the immortalized cell lines 3T3 A, LA9 and A9 4.5-6\% of the rings contained dislocated $\mathrm{K}^{-}$chromosomes. In the tumor cell lines HeLa and MBT an increase of up to $10 \%$ was observed. Thus, in general, a correlation between malignancy of these cells and the occurrence of dislocated $\mathrm{K}^{-}$chromosomes could be established. Furthermore, we investigated whether

Fig. 1. Metaphase ring arrangement of N18 mouse cells. (a) Visualization of kinetochores by CREST antibody staining. Note the presence of paired kinetochore signals at one displaced chromosome. (b) Visualization of centromeric DNA by in situ hybridization with mouse minor satellite DNA, showing the presence of centromeric DNA at the dislocated chromosome. 

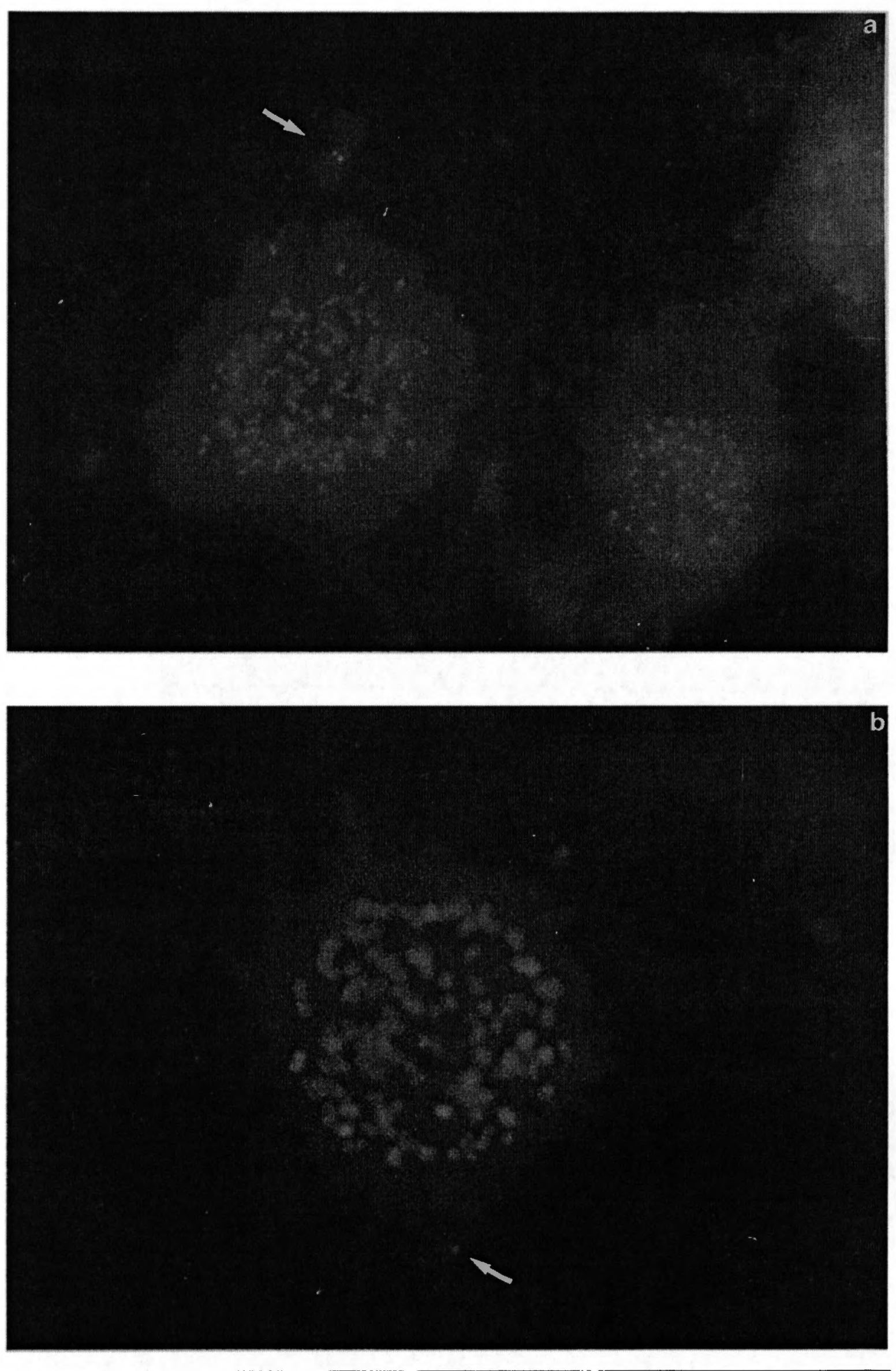


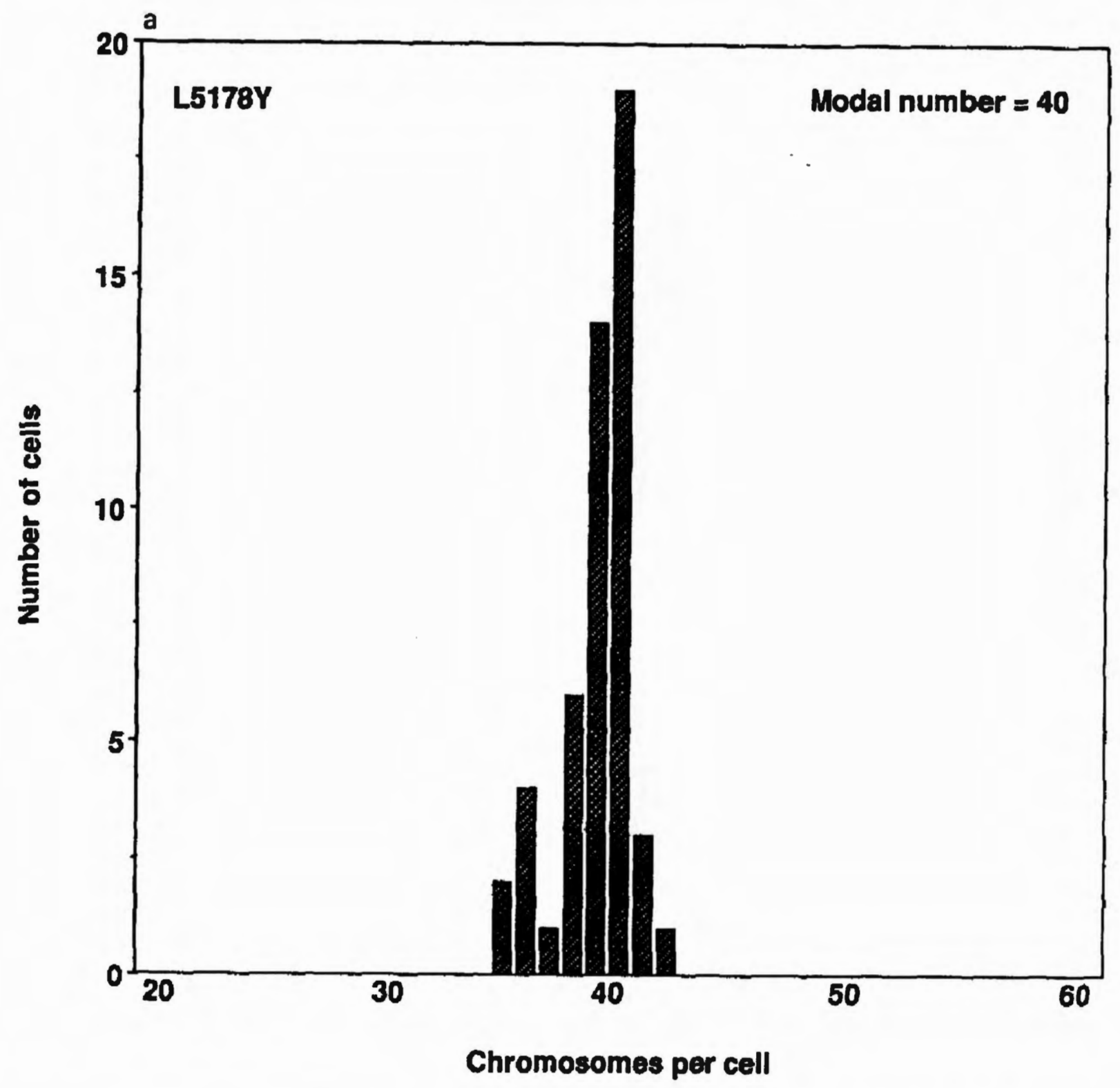

Fig. 2. Histograms showing the distribution of chromosome numbers in different mouse cell lines. Between 50 and 100 cells were evaluated for each cell line. Data for LA9 (b), A9 (c) and MBT (f) are from Vig et al. [4]. L5178Y (a), L929 (d) and N18 (e) investigated in this study.

the absence of kinetochore proteins is due to a lack of centromere DNA sequences. We performed in situ hybridization in N18 cells (Fig. 1) with a minor, satellite probe (located at the kinetochore) and with a human centromeric probe cocktail (Oncor/ Dianova, Hamburg, Germany) in HeLa cells. Our results show that in N18 cells (two different preparations) 10 of 23 (44\%) dislocated chromosomes failed to show a kinetochore signal, but only eight (35\%) did not show a centromere signal. Similar results (60\% $\mathrm{K}^{-}$chromosomes vs. $49 \%$ centromere-negative chromosomes) were obtained with HeLa cells. 


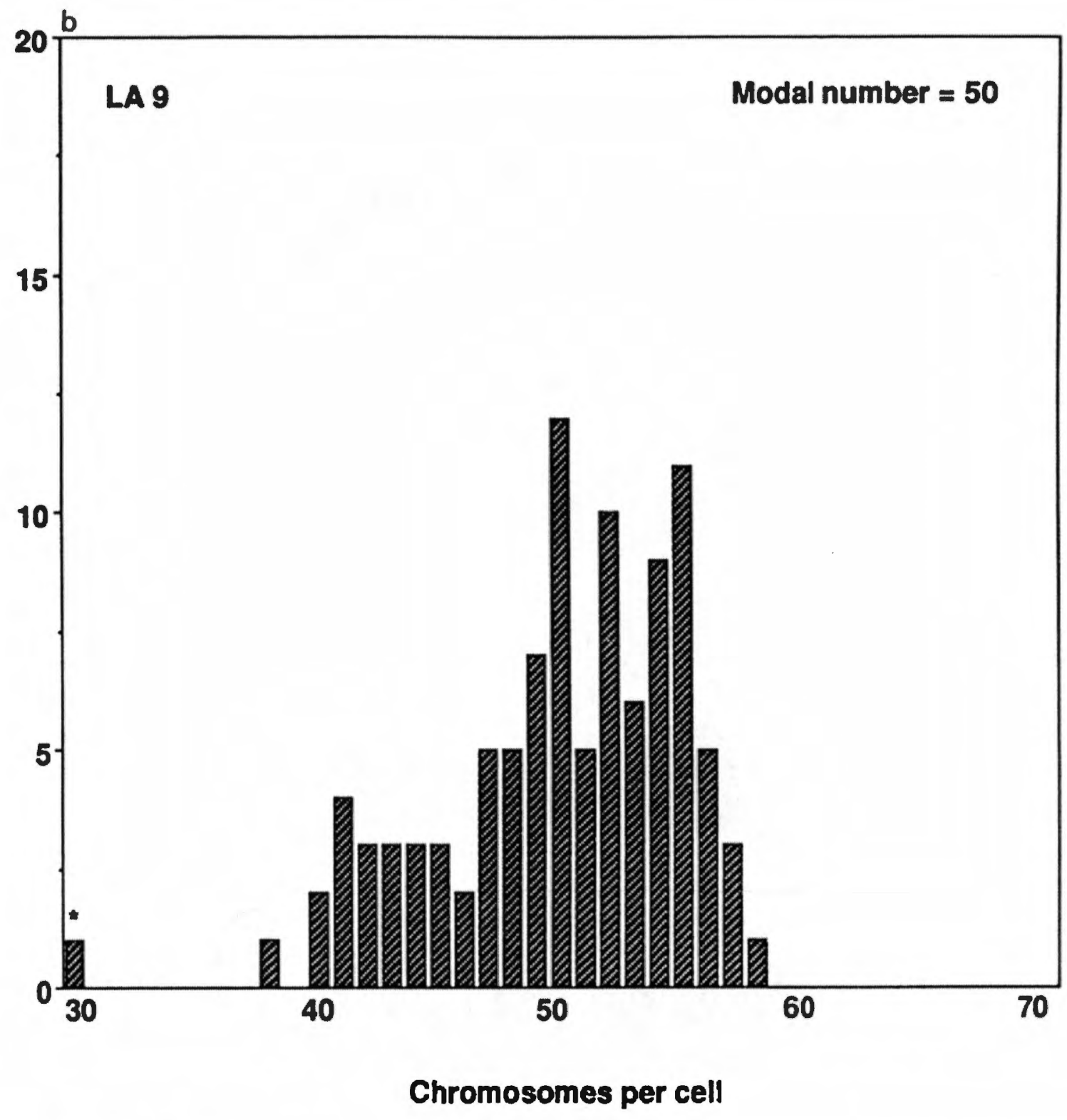

Distribution of chromosome numbers

We investigated the numerical distribution of chromosomes around the modal (most frequent) chromosome number in the mouse cell lines L5178Y, L929 and N18 and compared them to the previously investigated mouse cell lines LA9, A9 and MBT (Fig. 2a-f). L5178Y cells showed a low frequency $(x)$ of deviations from the modal chromosome number. LA9, A9 and L929 showed more frequent deviations (xx) and in N18 and MBT the most frequent numerical deviations (xxx) were observed (as listed also in Table II).

Analysis of micronuclei in mouse cell lines

The micronucleus frequencies (micronuclei/2000 cells) in the six mouse cell lines investigated (Table II) correlated with the observed/known degrees of numerical deviations from the modal chromosome numbers (Fig. 2a-f): the frequencies increased in 


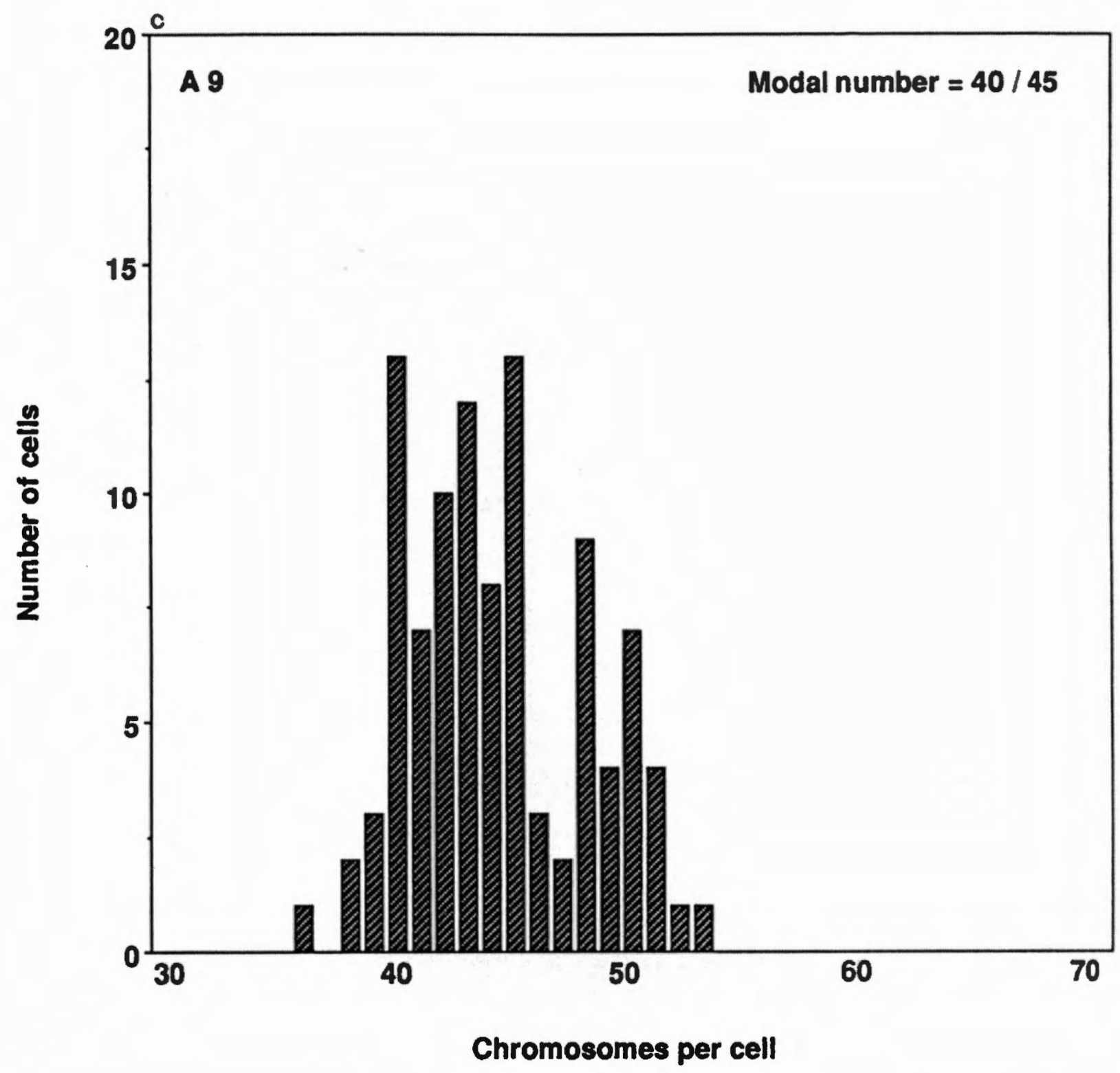

the same manner as the deviations in chromosome numbers. As revealed by kinetochore analysis, the frequencies of $\mathrm{K}^{-}$micronuclei increased concurrently.

\section{DISCUSSION}

Since the existence of chromosomes without kinetochores was recently reported [2], we investigated whether such $\mathrm{K}^{-}$chromosomes could be related to the variability in chromosome number and hence the genesis of aneuploidy. In a previous study, we reported that in three mouse cell lines the presence of such chromosomes correlated with the variability of chromosome number observed in these cell lines [4]. One of the aims of the present study was an extended investigation of this correlation using four additional mammalian cell lines. We chose SHE fibroblasts since this cell system 


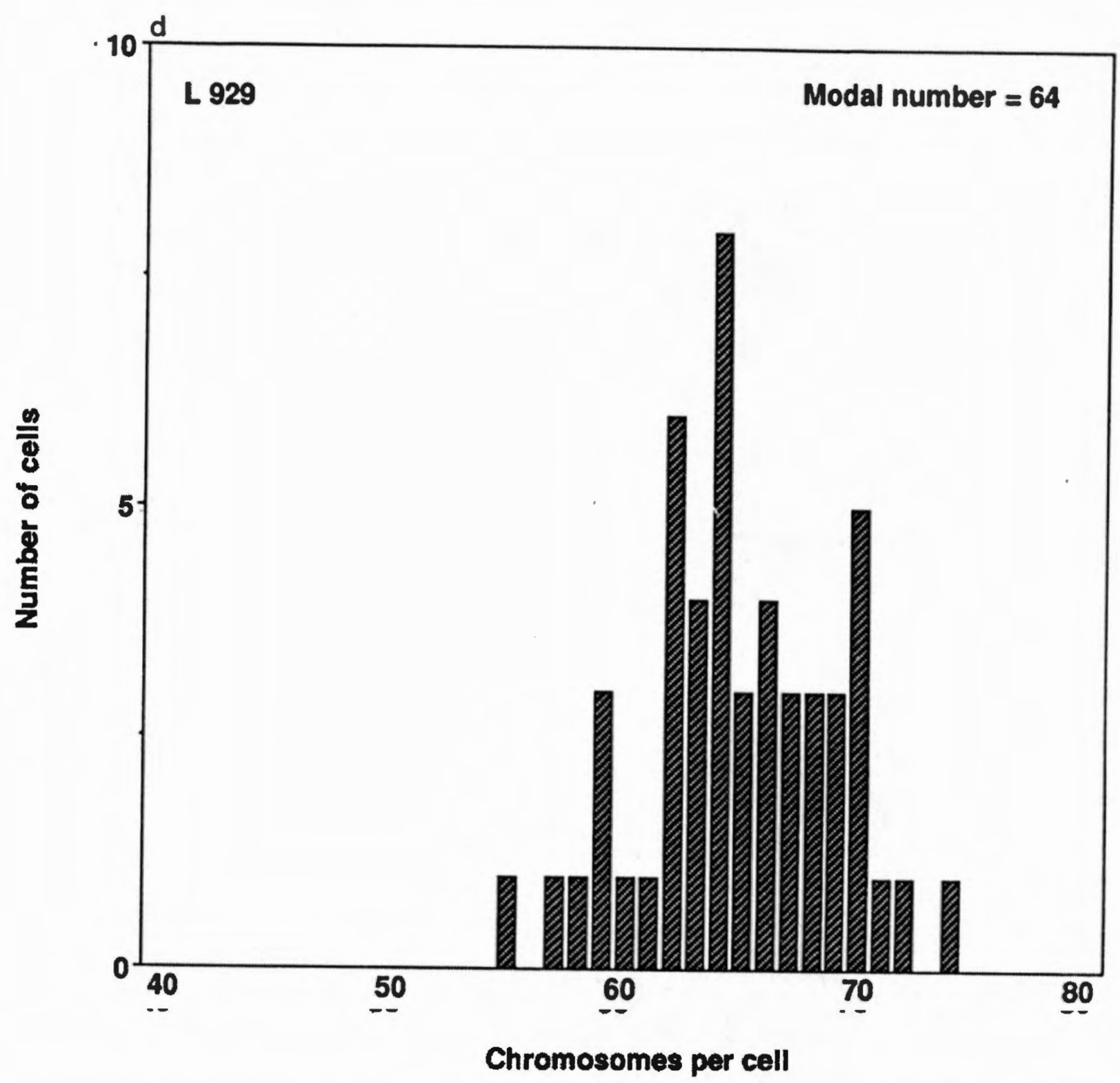

allows a direct comparison of chemically transformed and primary cells [7]. Moreover, primary SHE cells exhibit a very low variability in chromosome number [8]. The transformed SHE cell line investigated here exhibited a 6 -fold increase in the frequency of $\mathrm{K}^{-}$chromosomes displaced from the meta/anaphase ring arrangement compared to primary SHE cells. The observed low number of dislocated $\mathrm{K}^{-}$chromosomes in primary SHE cells may indicate that the occurrence of such chromosomes is a rare event in primary mammalian cells in general. In addition, we compared three immortalized mouse cell lines with two tumor cell lines. The observed frequencies of dislocated $\mathrm{K}^{-}$chromosomes further support our hypothesis [4] that the occurrence of such chromosomes is correlated with chromosome variability. $\mathrm{K}^{-}$chromosomes are most likely not attached to the spindle and, therefore, prone to loss.

Since our results demonstrate that centromeric DNA sequences can be present in the absence of antibody-stainable kinetochore proteins we conclude that the observed lack of kinetochores is not necessarily due to a lack of centromeric DNA. It seems 


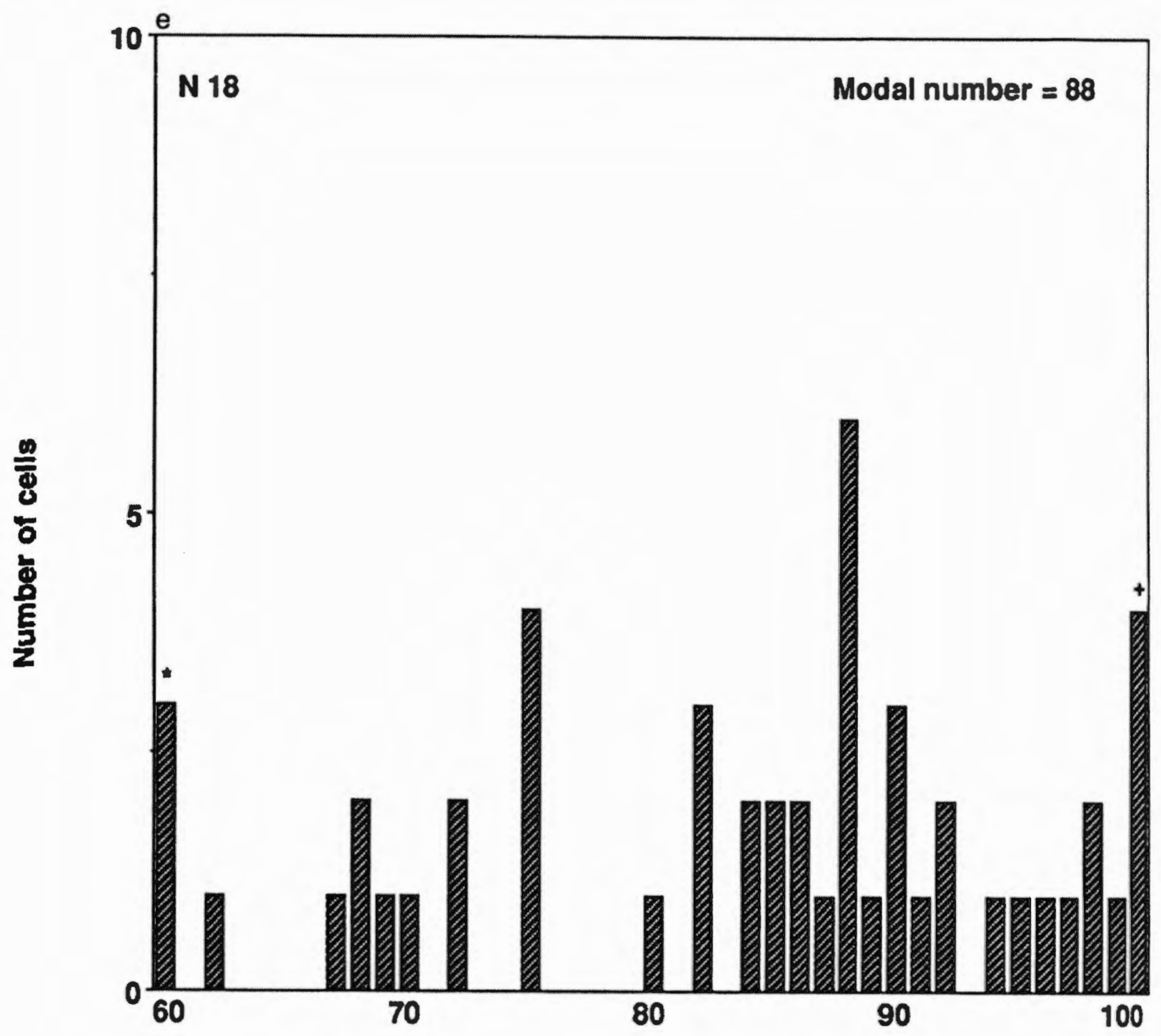

Chromosomes per cell

unlikely that minor satellite DNA (N18 cells) and the applied human centromere sequences are not involved in centromere function and, in this case, simply represent repetitive DNA sequences adjacent to the centromere. As discussed by Broccoli et al. [9], kinetochore binding to these chromosomes may be disturbed due to modifications (mutations or changes in methylation pattern) of the centromeric DNA.

Since the formation of micronuclei has been discussed as a possible mechanism for genomic loss $(10 ; 4)$ we investigated the frequency of micronuclei in six different cell lines of the same species (mouse). In parallel, we investigated the numerical distributions of chromosomes around the modal numbers. Our results revealed considerable differences between these cell lines: the increase in variability correlates with an increasing modal chromosome number. Furthermore, we also observed increasing micronucleus frequencies in the same order. Analysis for the presence of kinetochores revealed that the frequency of $\mathrm{K}^{-}$micronuclei increased likewise. In the cell lines with 


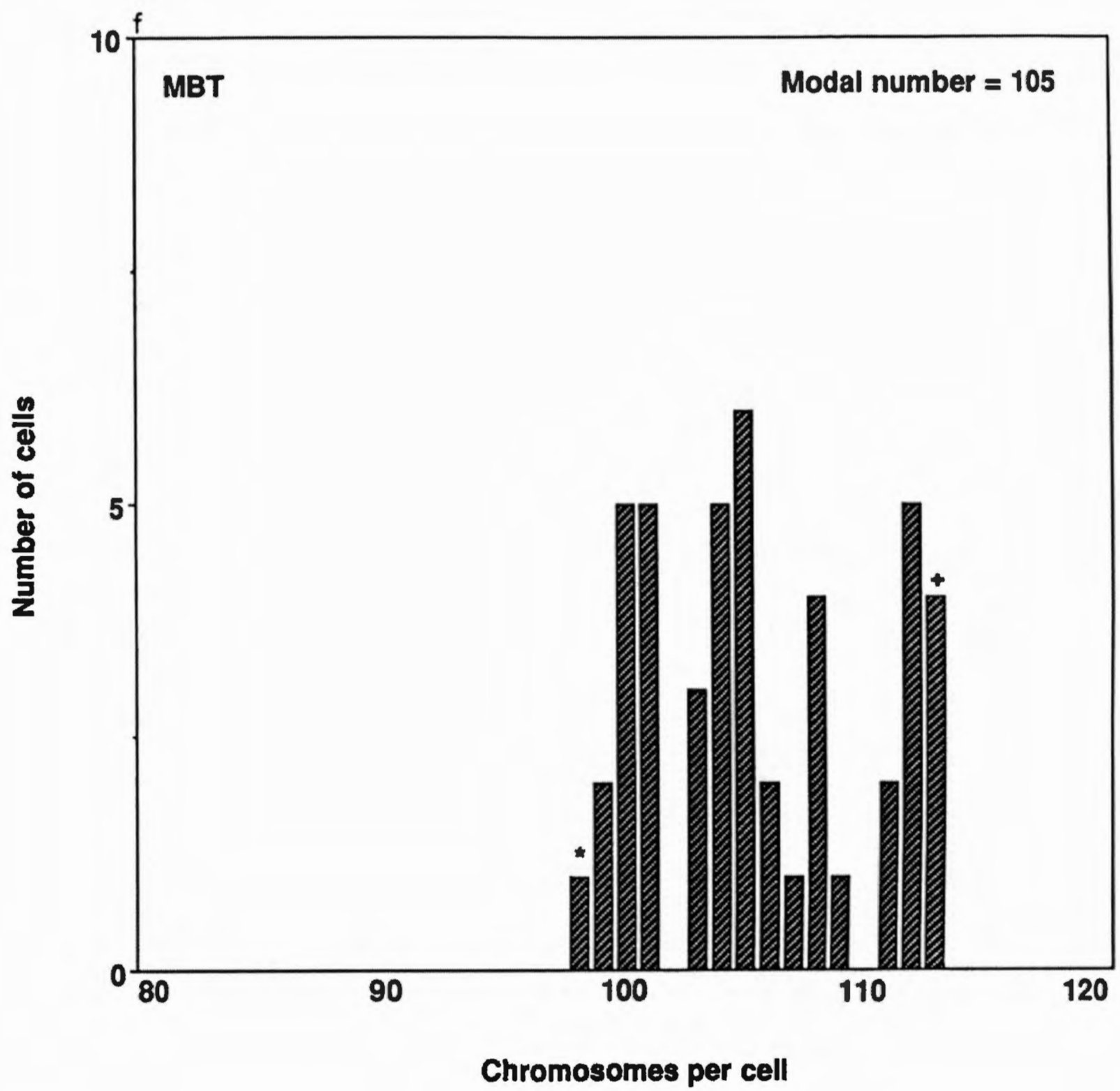

the highest modal chromosome numbers and variabilities the available amount of kinetochore protein may be limited.

The akinetochoric chromosomes would be displaced from the metaphase ring arrangement and most likely become incorporated into a micronucleus. Since the frequency of such $\mathrm{K}^{-}$chromosomes was not high enough to account for the observed variability in chromosome number as well as for the observed micronucleus frequencies (e.g., in MBT cells), an additional mechanism for the generation of micronuclei may exist. Vig et al. [4] reported that MBT cells do not exhibit spontaneous chromosomal breakage. Therefore, we conclude that micronuclei may also arise from events in interphase: MBT cells show an unusual chromatin organization [11] resulting in a donut- or crescent-shaped morphology. We recently observed that these cells are able 
TABLE II

COMPARISON OF SPONTANEOUS MICRONUCLEUS FREQUENCIES IN DIFFERENT MOUSE CELL LINES WITH THE FREQUENCIES OF DEVIATION FROM THEIR MODAL CHROMOSOME NUMBERS

\begin{tabular}{llccc}
\hline Cell line & $\begin{array}{l}\text { Chromosome } \\
\text { distribution }\end{array}$ & $\begin{array}{l}\text { Micronuclei/ } \\
\text { 2000 cells }\end{array}$ & $\mathbf{K}^{-}-\mathbf{M N}(\%)$ & $\begin{array}{l}\mathrm{K}^{-} \text {micronuclei/ } \\
\text { 2000 cells }\end{array}$ \\
\hline L5178Y & $\mathbf{x}$ & $3.7 \pm 0.6$ & $72.7^{2}$ & 2.7 \\
LA9 & $\mathbf{x x}$ & $15.2 \pm 1.5$ & $60.1 \pm 0.2$ & 9.1 \\
A9 & $\mathbf{x x}$ & $28.3 \pm 2.6$ & $62.7 \pm 8.6$ & 17.7 \\
L929 & $\mathbf{x x}$ & $56.6 \pm 8.3$ & $48.0 \pm 6.1$ & 27.2 \\
N18 & $\mathbf{x x x}$ & $113.0 \pm 14.2$ & $73.1 \pm 4.5$ & 82.6 \\
MBT & $\mathbf{x x x}$ & $158.8 \pm 12.3$ & $47.2 \pm 1.9$ & 74.9 \\
\hline
\end{tabular}

Micronuclei $(3 \times 100)$ were evaluated for the absence of kinetochores $\left(\mathrm{K}^{-}-\mathrm{MN}\right)$, except for ${ }^{\mathrm{a}}$ ( 200 micronuclei). Frequency of deviation: $x=$ low, $x x=$ medium, $x x x=$ high; see also Fig. 2a-f.

to change this morphology during interphase, possibly involving micronucleus formation (unpublished observation).

Nevertheless, a number of kinetochore bearing chromosomes $\left(\mathrm{K}^{+}\right)$was observed to be dislocated in metaphase and an increase of $\mathrm{K}^{+}$micronuclei was also observed. It is still an open question whether these are also associated with the genesis of aneuploidy since they still may be or may become reintegrated into the genome. However, the presence of the kinetochore signal does not exclude the absence or damage of a single kinetochore protein essential for kinetochore function.

\section{ACKNOWLEDGEMENTS}

This work was supported by the Sonderforschungsbereich 172 of the Deutsche Forschungsgemeinschaft. We thank Dr. W.J. Caspary for kindly providing L5178Y cells.

\section{REFERENCES}

1 Earnshaw, W.C. and Rothfield, N. (1985) Identification of a family of human centromere proteins using autoimmune sera from patients with scleroderma. Chromosoma 91, 352-357.

2 Vig, B.K. and Sternes, K. (1991) Centromeres without kinetochore proteins: another mechanism for origin of aneuploidy in neoplasia. Cancer Genet. Cytogenet. 51, 269-272.

3 Vig, B.K., Sternes, K. and Paweletz, N. (1991) Lack of detectable kinetochores on some chromosomes in mouse $x$ human hybrids. Eur. J. Cell Biol. 56, 374-380.

4 Vig, B.K., Yoo, H. and Schiffmann, D. (1991) Kinetochore proteins, peripheral location of chromosomes and nuclear budding: another look at the genesis of aneuploidy. Mutagenesis 6 (5), 361-367. 
5 Schiffmann, D., Reichert, D. and Henschler, D. (1984) Induction of morphological transformation and unscheduled DNA synthesis in Syrian hamster embryo fibroblasts by hexochlorobutadiene and its putative metabolite pentachlorobutenoic acid. Cancer Lett. 23, 297-305.

6 Potenberg, J., Schiffmann, D., Kahl, R., Hildebrandt, A.G. and Henschler, D. (1986) Modulation of benzo(a)pyrene-induced morphological transformation of Syrian hamster embryo cells by butylated hydroxytoluene and butylated hydroxyanisole. Cancer Lett. 33, 189-198.

7 Barrett, J.C. and Tsò, P.O.P. (1978) Evidence for the progressive nature of neoplastic transformation in vitro. Proc. Natl. Acad. Sci. USA 75, 3761.

8 Barrett, J.C., Hesterberg, T.W., Oshimura, M. and Tsutsui, T. (1985) Role of chemically induced mutagenic events in neoplastic transformation of Syrian hamster embryo cells. In: Carcinogenesis - a Comprehensive Survey, Vol. 9, pp. 123-137.

9 Broccoli, D., Miller, O.J. and Miller, D.A. (1990) Relationship of mouse minor satelite DNA to centromere activity. Cytogen. Cell Genet. 54, 182-186.

10 Schiffmann, D. and DeBoni, U. (1991) Dislocation of chromatin elements in prophase induced by diethylstilbestrol: a novel mechanism by which micronuclei can arise. Mutat. Res. 246, 113-122.

11 Vig, B.K. and Richards, B. (1992) Dispersal of chromatin from the nuclear core: a novel phenomenon in a mouse brain tumor cell line. Environ. Molec. Mutagen. 19, Suppl. 20,67. 